\title{
The growth response to GH treatment is greater in patients with SHOX enhancer deletions compared to SHOX defects
}

\author{
S H Donze', C R Meijer ${ }^{1}$, S G Kant ${ }^{2}$, G R J Zandwijken ${ }^{3}$, A H van der Hout ${ }^{4}$, \\ R M L van Spaendonk ${ }^{5}$, A M W van den Ouweland ${ }^{6}$, J M Wit ${ }^{1}$, M Losekoot ${ }^{2}$ and \\ W Oostdijk ${ }^{1}$
}

Departments of ${ }^{1}$ Pediatrics and ${ }^{2}$ Clinical Genetics, Leiden University Medical Center, PO Box 9600, 2300 RC Leiden, The Netherlands, ${ }^{3}$ Dutch Growth Research Foundation ('Stichting Kind en Groei'), PO Box 23068, 3001 KB Rotterdam, The Netherlands, ${ }^{4}$ Department of Genetics, University Medical Center Groningen, University of Groningen, PO Box 30.001, 9700 RB Groningen, The Netherlands, ${ }^{5}$ Department of Clinical Genetics, VU University Medical Center, PO Box 7057, 1007 MB Amsterdam, The Netherlands and ${ }^{6}$ Department of Clinical Genetics, Erasmus Medical Center, PO Box 2060, 3000 CB Rotterdam, The Netherlands

\author{
Correspondence \\ should be addressed \\ to W Oostdijk \\ Email \\ w.oostdijk@lumc.nl
}

\begin{abstract}
Objective: Short stature caused by point mutations or deletions of the short stature homeobox (SHOX) gene (SHOX haploinsufficiency (SHI)) is a registered indication for GH treatment. Patients with a SHOX enhancer deletion (SED) have a similar phenotype, but their response to GH is unknown. It is uncertain if duplications of SHOX or its enhancer (SDUP) cause short stature. This study aimed to describe the clinical characteristics and growth response to $\mathrm{GH}$ treatment in patients with aberrations of SHOX and its enhancers.

Design: In this retrospective multi-center study (2002-March 2014) clinical information was available from 130 patients (72 SHI, 44 SED, and 14 SDUP) of whom 52 patients were treated with GH. We evaluated height, sitting height (SH), arm span, dysmorphic features and indicators of the growth response to GH (delta height SDS, height velocity, and index of responsiveness).

Results: Patients with SEDs showed similar HtSDS to patients with SHI $(-2.3$ and -2.6 , respectively, $P=0.2)$, but they were less disproportionate (SH/height ratio SDS 2.0 vs $3.1(P<0.01)$ and extremities/trunk ratio 2.57 vs $2.43(P=0.03))$. The 1 st year growth response to $\mathrm{GH}$ treatment was significantly greater in prepubertal patients with SEDs than SHI. None of the patients with an SDUP was disproportionate and SDUP cosegregated poorly with short stature; their growth response to GH treatment $(n=3)$ was similar to the other groups.

Conclusions: Patients with SEDs are equally short, but less disproportionate than patients with SHI, and show a greater response to $\mathrm{GH}$.

\section{Introduction}

The short stature homeobox $(S H O X)$ gene encodes a homeodomain protein that acts as a transcriptional activator (1). It is strongly expressed in the developing limb and is thought to contribute to longitudinal growth by regulating proliferation and differentiation of the chondrocytes in the growth plate (1). The gene is located on the short arm of the X-and Y-chromosomes in the pseudoautosomal region 1 and escapes $\mathrm{X}$-inactivation, which leads to a pseudoautosomal inheritance pattern $(2,3,4)$. A homozygous deletion or point mutation of $S H O X$ results in an extreme phenotype of osteodysplasia called Langer syndrome. The classical presentation of $S H O X$ haploinsufficiency (SHI), due to heterozygous SHOX defects, is Léri-Weill dyschondrosteosis (LWD), characterized by the

Published by Bioscientifica Ltd. 
typical clinical triad of short stature, mesomelia and Madelung deformity. However, SHOX defects can also be found in short children without dysmorphic features and normal body proportions, who had initially been considered as having idiopathic short stature.

Recent studies have shown that deletions in the downstream enhancer region of $S H O X$, and (less frequently) in the upstream enhancer region (SHOX enhancer deletions (SEDs)), can result in a clinical picture similar to that of SHI $(5,6,7,8,9,10)$. In about two-thirds of cases LWD is caused by intragenic point mutations or deletions of the complete coding sequence of SHOX, and in one-third of cases by deletions in the enhancer sequences in the $3^{\prime}$ - or $5^{\prime}$-flanking region of $S H O X$, leaving the gene itself intact (11).

A duplication of SHOX would be expected to be associated with tall stature. The relatively tall height of individuals with Klinefelter syndrome and XXX syndrome is indeed thought to be caused by increased $S H O X$ expression. Surprisingly, duplications of $S H O X$ and/or its enhancers (SDUPs) have also been found in short children $(12,13,14)$, although only in a few of them additional clinical features characteristic for SHOX dysfunction were noted, and parents carrying the duplication were usually of normal stature. Therefore, the pathogenicity of SDUPs is still uncertain $(12,13,14,15)$.

Growth hormone (GH) treatment is registered for children with short stature caused by SHI, currently defined as a deletion or point mutation in SHOX itself, based on studies showing a significant increase in height SDS (HtSDS) during the first 2 years of treatment $(16,17)$. The effect of GH treatment, however, had not yet been evaluated for patients with an SED or SDUP (17).

The principal aim of this study is to investigate whether the effect of GH treatment in children with an SED is comparable to that in children with SHI. Because of the phenotypic similarity between the two groups $(2,10)$, we hypothesized that the effect of GH treatment in children with a deletion of the downstream or upstream enhancer region of $S H O X$ would be similar to the effect in children with a SHOX point mutation or deletion. In addition, the clinical characteristics of patients with point mutations or deletions of the SHOX gene, deletions of the SHOX enhancer regions, or duplications of $S H O X$ or its enhancer were investigated.

\section{Subjects and methods}

\section{Study design}

In this retrospective study from 2002 onwards, patients were included who were diagnosed with SHI, SEDs, and
SDUPs in the Laboratories for Diagnostic Genome Analysis of the Departments of Clinical Genetics of the Leiden University Medical Center (LUMC, Leiden), VU University Medical Center (VUMC, Amsterdam), Erasmus Medical Center (EMC, Rotterdam), and University Medical Center Groningen (UMCG, Groningen) in The Netherlands.

Deletions and duplications of $S H O X$ and its enhancer regions were diagnosed with multiplex ligation probe amplification (MLPA) with the P018 kit from MRCHolland (Amsterdam, The Netherlands) using standard procedures. Most deletions and duplications were characterized with the P018-D1 MLPA kit but other versions of the kit had been used as well. A graphical picture of the position of the various probes is shown in Supplementary Figure 1, see section on supplementary data given at the end of this article. If a deletion of the SHOX gene was detected, Sanger sequencing was not performed. If MLPA analysis revealed no deletions in the SHOX gene or if it revealed a deletion of the SHOX enhancer region, Sanger sequence analysis of the complete coding region of SHOX, including intron-exon boundaries, was performed (18). The SHOXa isoform was sequenced using the Ensembl transcript 'ENST00000381575' (NM_000451.3).

In general, patients with short stature were referred for DNA analysis by pediatric endocrinologists or clinical geneticists. After approval from the Medical Ethical Committee of the Leiden University Medical Center, patients diagnosed with an aberration of SHOX or its enhancer region were asked to participate in this study. Written informed consent was obtained from the participating subjects or from the subjects' parents.

\section{Participants}

Until March 2014, 390 patients were diagnosed with defects of SHOX or its enhancer regions (Fig. 1). Patients living in other countries than The Netherlands $(n=23)$ and patients in whom the SHOX variants were considered non-pathogenic $(n=27)$ were not asked to participate in the study. Eight patients were not included because the treating physicians were reluctant to ask the patients and their parents for permission, and another eight patients were diagnosed with other disorders also contributing to short stature: multiple epiphyseal dysplasia $(n=2)$, Smith Magenis syndrome $(n=1)$, insulin-like growth factor 1 (IGF1) mutation ( $n=1)$, Albright's hereditary osteodystrophy $(n=1)$, an additional deletion of chromosome 6 $(n=1)$, bio-inactive $\mathrm{GH}(n=1)$, and an isodicentric Y-chromosome $(n=1)$. The affected parents of these patients were excluded as well $(n=4)$. 


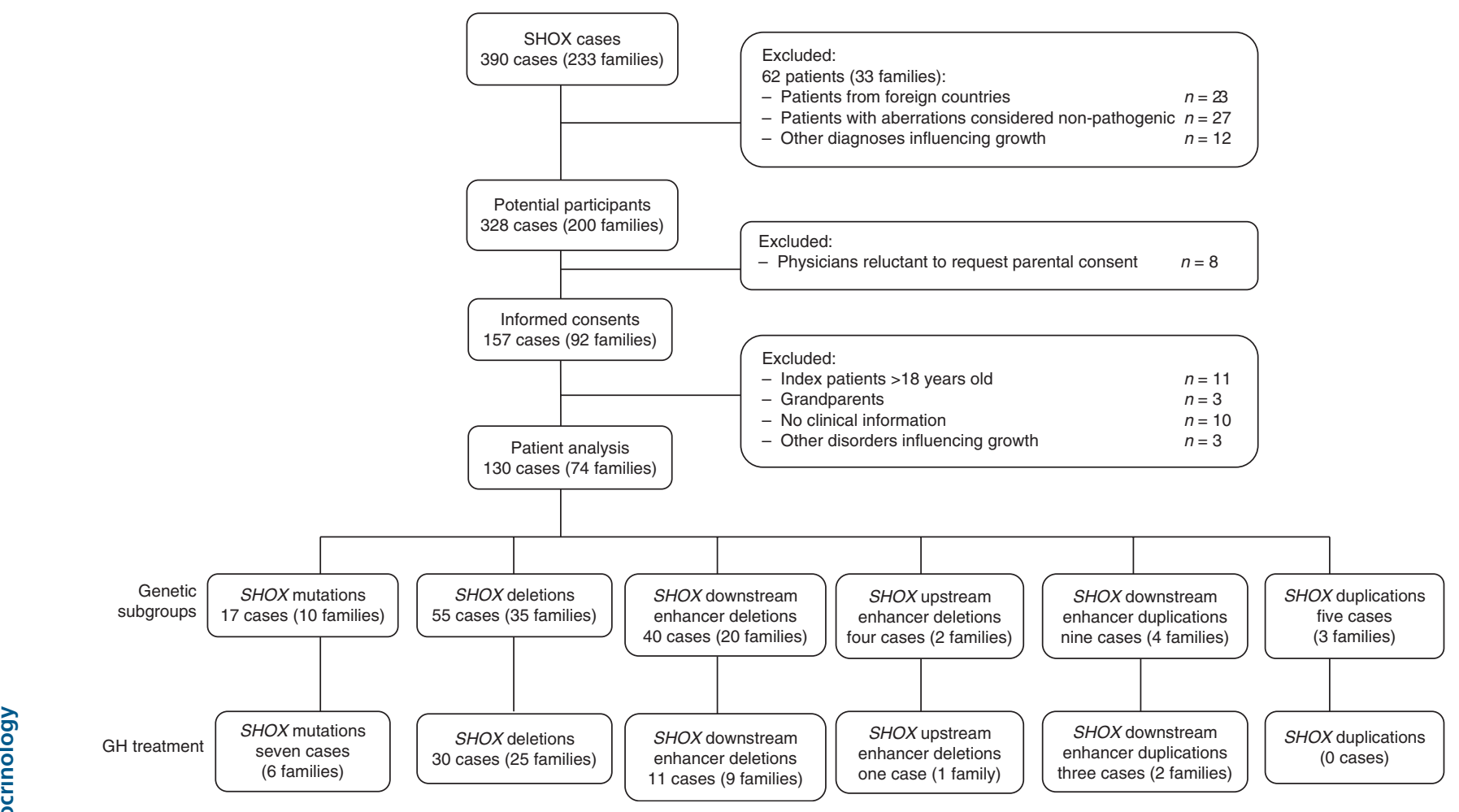

Figure 1

Flow chart of study design and patient distribution.

The remaining 320 patients were asked to participate in this study. At closure of the database, we had received 157 informed consent forms and collected clinical information from 130 patients (88 probands, from 74 families). Fifty-six patients from 47 families were treated with a variety of commercially available recombinant GH products.

\section{Clinical assessment}

Clinical data from the referring hospital and the Dutch National Registry for GH Treatment in children located at the Dutch Growth Research Foundation ('Stichting Kind en Groei', Rotterdam, The Netherlands) were collected from all patients who provided informed consent. These included: birth length, birth weight, head circumference at birth, height, weight, sitting height (SH), arm span, forearm length, dysmorphic signs (Madelung deformity, cubitus valgus, bowing of the radius and ulna or muscular hypertrophy), serum IGF1 and IGFBP3, and skeletal age. Information about linear growth, serum IGF1, IGFBP3, and skeletal age, was collected every $12 \pm 3$ months up to 4 years for patients treated with GH. From the parents, height, body proportions, and SHOX test results were obtained.

\section{Patient analysis}

Patients were divided into three groups: group 1 consisted of patients with SHI; group 2 of patients with a SED; and group 3 of patients with an SDUP. Subgroups of each group were treated with GH (Fig. 1). For all patients, we analyzed the available clinical data and compared the clinical data of probands to those of their parents.

To assess the effect of GH therapy in patients with a deletion in the SHOX enhancer region and patients with a SHOX defect, we used four outcome measures for the first 4 years of treatment. The first three of these, the difference in height SDS ( $\Delta \mathrm{HtSDS})$, height velocity (HV, $\mathrm{cm} /$ year) and height velocity as SDS (HVSDS) for age (based on the Swiss longitudinal growth study (19)), are parameters of the growth response. The fourth measure is the 'index of responsiveness (IoR)', based on prediction models for growth during the first 4 years of GH treatment in girls with Turner syndrome (20). We chose this approach because the growth response to GH treatment is reported 
as being similar for patients with $S H O X$ defects and patients with Turner syndrome (21). Because previous studies have shown that prepubertal growth is largely independent of sex, we applied the prediction models for Turner syndrome in males and females (22). For each patient, the predicted growth velocity (based on clinical predictors of the growth response) as described by Ranke et al. $(20,23,24)$ was subtracted from the observed height velocity and transformed into a studentized residual. A studentized residual above 0 is an indicator of a relatively high responsiveness to GH treatment, adjusted for potential confounders. Strictly speaking, the prediction formulas for Turner syndrome are not applicable for children who undergo spontaneous puberty. However, since prepubertal children only represented a relatively small part of the total number of patients treated with GH, we also applied the formulas to all patients, irrespective of their pubertal status, and compared the results between groups 1 and 2 .

Secondary outcome measures included the increase in bone age/calendar age ratio during $\mathrm{GH}$ therapy $(\triangle \mathrm{BA} / \Delta \mathrm{CA}$ ratio), the increase in serum IGF1 SDS during GH treatment ( $\triangle \mathrm{IGF1}$ ) and the effect of GH on body proportions (the change in SH/height SDS, $\Delta \mathrm{SH} /$ height SDS). Skeletal age, serum IGF1, and SH/height SDS closest to the start of GH were compared to the last measured BA, serum IGF1 and SH/height SDS. All analyses were carried out separately for patients who remained prepubertal during the observation period and for all patients. Results for prepubertal children were compared to published data on the growth response to GH treatment in patients with SHI. In this study by Blum et al. (21), the percentage of SHOX deletions and mutations was similar to our study, as was the GH dose.

\section{Statistical analysis}

HtSDS and SH/height SDS were calculated based on Dutch nation-wide references $(25,26)$. Height velocity SDS was calculated based on the Swiss longitudinal study (19). Midparental height adjusted for gender, assortative mating, and parent-offspring correlations, adapted to the most recent Dutch population reference (26), was expressed as SDS (conditional target HtSDS) (27). BMI SDS was calculated based on the 1980 Dutch nation-wide growth study (28). Birth weight and birth length for gestational age were transformed to SDS values using the standards of Niklasson et al. (29). IGF1 and IGFBP3 data were collected as measured by local laboratories. Since the IGF1 assays in The Netherlands have been harmonized and titrated on the original assay used for preparing reference data (30), levels were expressed as SDS. BA of patients was analyzed as reported by the treating physicians. The extremities/trunk ratio, which compares extremities length to trunk length, was calculated as follows: (calculated subischial length + arm span)/SH (31).

To calculate the predicted height velocity, according to the prediction model for Turner syndrome, height and weight were converted to SDS using the height standards of Prader et al. (19) and the weight standards of Freeman et al. (32), and mid-parental height was calculated as (father's HtSDS + mother's HtSDS)/1.61 (33).

Data were expressed as means and S.D. and compared between groups with the Student's $t$-test for continuous variables with a Gaussian distribution and $\chi^{2}$ test for categorical variables. If continuous variables were not normally distributed the Mann-Whitney $U$ test was used. Significance was considered at the $5 \%$ level $(P<0.05)$.

\section{Results}

Of the 88 probands (from 74 families), 55 (from 42 families) inherited the mutation from one of the parents, 26 from their father (47\%) and 29 from their mother (53\%). Seven patients had a de novo defect, and for the remaining cases $(n=26)$ no information was available.

\section{Mutations of SHOX and its enhancer}

Of the 88 probands, 54 were diagnosed with a point mutation ( $n=11$, from ten families) or deletion $(n=43$, from 35 families) of SHOX (SHI, group 1). Growth data were similar, except for a slight but statistically significant difference in HtSDS ( -3.0 for SHOX point mutations, -2.5 for SHOX deletions, $P=0.04$ ). There was no statistically significant correlation between HtSDS of the index cases and that of the affected or unaffected parents. In order to increase statistical power, we clustered both types of $\mathrm{SHI}$ in one group.

There were 26 patients (from 22 families) with a deletion of the SHOX downstream or upstream enhancer region (SED, group 2). Table 1 shows the clinical characteristics at first visit of groups 1 and 2. Children from group 2 were less disproportionate than children from group 1 (SH/height SDS 2.0 vs 3.1, $P<0.01$ and extremities/trunk ratio 2.57 vs $2.43, P=0.03$ ). Madelung deformity was present in 23 out of 74 individuals (31\%), 17 in group 1 and six in group $2(P=0.11)$. Information on other dysmorphic features, such as cubitus valgus, bowing of the forearm and muscular hypertrophy were often not reported and could therefore not be compared between groups. 
Table 1 Clinical characteristics at first visit in patients with SHOX mutations and deletions and SHOX enhancer deletions, mean (s.D.).

\begin{tabular}{|c|c|c|c|c|c|c|c|c|}
\hline Clinical characteristics & $n$ & All patients & Range & $n$ & $\begin{array}{l}\text { SHOX mutations } \\
\text { or deletions }\end{array}$ & $n$ & $\begin{array}{c}\text { SHOX upstream } \\
\text { and downstream } \\
\text { enhancer } \\
\text { deletions }\end{array}$ & $\boldsymbol{P}^{*}$ \\
\hline Age at first visit (years) & 80 & $8.35(3.6)$ & $1.2 ; 16.2$ & 54 & $8.3(3.5)$ & 26 & $8.5(3.7)$ & 0.839 \\
\hline Male/female & & $34 / 46$ & & & 23/31 & & $11 / 15$ & 0.981 \\
\hline Birth weight SDS & 66 & $-0.4(1.3)$ & $-3.3 ; 3.2$ & 43 & $-0.4(1.3)$ & 23 & $-0.3(1.3)$ & 0.728 \\
\hline Birth length SDS & 37 & $-1.1(1.2)$ & $-4.3 ; 1.5$ & 23 & $-1.0(1.2)$ & 14 & $-1.1(1.4)$ & 0.823 \\
\hline Height SDS & 80 & $-2.5(0.8)$ & $-4.4 ;-0.3$ & 54 & $-2.6(0.8)$ & 26 & $-2.3(0.8)$ & 0.111 \\
\hline $\begin{array}{l}\text { Conditional target } \\
\text { height SDS }\end{array}$ & 74 & $-1.0(0.6)$ & $-2.9 ; 0.7$ & 50 & $-1.0(0.6)$ & 24 & $-0.9(0.5)$ & 0.647 \\
\hline $\begin{array}{l}\text { Sitting height/height } \\
\text { ratio SDS }\end{array}$ & 72 & $2.8(1.3)$ & $-0.1 ; 5.5$ & 50 & $3.2(1.1)$ & 22 & $1.9(1.3)$ & $<0.01$ \\
\hline Armspan/height ratio & 33 & $0.95(0.03)$ & $0.87 ; 1.01$ & 21 & $0.95(0.03)$ & 12 & $0.96(0.03)$ & 0.365 \\
\hline BMI SDS & 76 & $0.4(1.0)$ & $-2.0 ; 2.7$ & 51 & $0.5(0.9)$ & 25 & $0.1(1.1)$ & 0.069 \\
\hline Extremities/trunk ratio ${ }^{a}$ & 32 & $2.48(0.2)$ & $2.06 ; 2.80$ & 21 & $2.43(0.2)$ & 11 & $2.57(0.2)$ & 0.028 \\
\hline \multicolumn{9}{|l|}{$\begin{array}{l}\text { Comparison to parents' } \\
\text { phenotype: }\end{array}$} \\
\hline Height SDS affected parent & 49 & $-2.2(0.9)$ & $-4.8 ;-0.3$ & 28 & $-2.4(0.9)$ & 21 & $-1.9(0.9)$ & 0.032 \\
\hline $\begin{array}{l}\text { Sitting height/height ratio } \\
\text { SDS affected parent }\end{array}$ & 23 & $2.7(1.7)$ & $0.5 ; 6.1$ & 9 & $3.3(1.4)$ & 14 & $2.3(1.8)$ & 0.168 \\
\hline $\begin{array}{l}\text { Height SDS - TH SDS (de } \\
\text { novo mutations) }\end{array}$ & 7 & $-1.9(0.7)$ & $-3.2 ;-1.1$ & 6 & $-1.9(0.7)$ & 1 & -2.1 & \\
\hline $\begin{array}{l}\text { Height SDS - height SDS } \\
\text { affected parent }\end{array}$ & 46 & $-0.3(1.1)$ & $-2.2 ; 2.6$ & 25 & $-0.2(0.9)$ & 21 & $-0.5(1.3)$ & 0.419 \\
\hline $\begin{array}{l}\text { Height SDS - height SDS } \\
\text { unaffected parent }\end{array}$ & 43 & $-1.7(0.9)$ & $-3.5 ; 0.2$ & 24 & $-1.7(0.9)$ & 19 & $-1.6(1.0)$ & 0.579 \\
\hline
\end{tabular}

* $P$ value from $t$-test comparing patients with $S H O X$ mutations and deletions to patients with $S H O X$ upstream and downstream enhancer deletions. 'Binders' extremities/trunk ratio compares the extremities length to the trunk length and is calculated as follows: (calculated subischial length + arm span) /sitting height. The normal values are dependent on height. A lower score indicates more severe disproportionate stature.

HtSDS of patients with a de novo mutation was compared to the conditional target HtSDS. In case of a familial mutation, HtSDS was compared to HtSDS of the affected and the unaffected parent (Table 1). As expected, in both groups the proband's HtSDS was closer to HtSDS of the parent carrying the SHOX aberration than to the other parent's HtSDS. Affected parents in group 2 were significantly less short than affected parents in group $1(-1.9$ vs $-2.4, P=0.03)$.

\section{Duplications of SHOX and its enhancer}

The clinical features of the eight patients (from seven families) with duplications of $S H O X$ or its enhancer (group 3) are shown in Table 2. In none of them was $\mathrm{SH} /$ height SDS above +2 SDS, and only one parent carrying the duplication was short. The duplicated SHOX probes of these patients are shown in Supplementary Figure 1.

\section{Growth response to $\mathrm{GH}$}

From the 56 probands who were treated with biosynthetic $\mathrm{GH}$, we obtained clinical information during $\mathrm{GH}$ treatment about 37 patients from group 1 (66\%), 12 patients from group 2 (22\%), and three patients from group 3 (5\%) (Fig. 1). Table 3 shows the baseline data and growth response for patients from groups 1 and 2 who remained prepubertal. For comparing $\mathrm{HV}$ and $\mathrm{IoR}$ between groups 1 and 2, we only included patients of whom HV before start of GH was available. Except for a small, but statistically significant, difference in $\mathrm{HV}$ before start of GH treatment (5.0 for group 1 and 6.1 for group 2, $P=0.02)$, there were no significant differences between the two groups at start of GH. In the 1st year, all three parameters of growth response, $\Delta \mathrm{HtSDS}, \mathrm{HV}$, and HV SDS were significantly greater in group 2 . The difference between the two groups for the IoR was just above the level of statistical significance (Table 3). A graphical representation of these data is shown in Figs 2 and 3, showing HtSDS and $\mathrm{HV}$ in response to $\mathrm{GH}$ treatment for four cohorts of children who remained prepubertal during GH treatment for 1-4 years, in comparison to data reported by Blum et al. (16). In both groups the growth response was greatest in the 1st year of GH treatment and declined thereafter. 
Table 2 Clinical characteristics of patients with SHOX or SHOX enhancer duplications at first visit $(n=8)$. The size of the duplications are shown in Supplementary Figure 1.

\begin{tabular}{l}
\hline Clinical characteristics \\
\hline Age at first visit (years) \\
Male (M)/female (F) \\
Birth weight SDS \\
Birth length SDS \\
Height SDS \\
Conditional target height SDS \\
Sitting height/height ratio SDS \\
Armspan/height ratio \\
BMI SDS \\
IGF1 SDS \\
IGFBP3 SDS \\
Parents' phenotype: \\
Carrier parent \\
Height SDS \\
Sitting height/height ratio SDS \\
Unaffected parent \\
Height SDS \\
Sitting height/height ratio SDS \\
Growth response and responsiveness \\
First year of GH \\
$\Delta$ Height SDS \\
HV (cm/year) \\
loR
\end{tabular}

\begin{tabular}{c}
\hline $\mathbf{1}^{\mathrm{a}}$ \\
\hline 5.6 \\
$\mathrm{~F}$ \\
- \\
- \\
-2.4 \\
- \\
1.5 \\
- \\
0.6 \\
0.8 \\
0.6
\end{tabular}

\begin{tabular}{c}
\hline $\mathbf{2}$ \\
\hline 3.3 \\
F \\
- \\
- \\
-3.5 \\
-0.9 \\
- \\
- \\
0.2 \\
- \\
-
\end{tabular}

\begin{tabular}{cc}
\hline $\mathbf{3}$ \\
\hline 11.9 \\
$\mathrm{~F}$ \\
0.22 \\
0.9 \\
-2.4 \\
-0.8 \\
1.8 \\
0.94 \\
-1.2 \\
-2.7 \\
-0.1
\end{tabular}

$\frac{4}{4.5}-$

\begin{tabular}{c}
\hline $\mathbf{5}^{\mathrm{b}, \mathrm{c}}$ \\
\hline 9.2 \\
$\mathrm{M}$ \\
-0.5 \\
- \\
-2.2 \\
-1.1 \\
0.7 \\
- \\
-1.5 \\
-1.4 \\
-2.7
\end{tabular}

$\frac{6^{\mathrm{b}, \mathrm{c}}}{5.5}$

\section{$-1.7$}

$-1.1$

$-2.4$

$-1.7$

$-0.5$

$\frac{7^{\mathrm{b}}}{3.8}$

8

$-$

$-$

$-1.9$

$-$

$\begin{array}{ccc}- & 1.0 & -0.4 \\ - & - & - \\ - & -3.5 & -1.5 \\ - & - & 3.2\end{array}$

-1.5
3.1
-3.0
1.8

$-1.4$

$-1.4$

$-2.5$

1.2

$-$

$-1.6$

$-1.6$

$-1.0$

$-0.5$

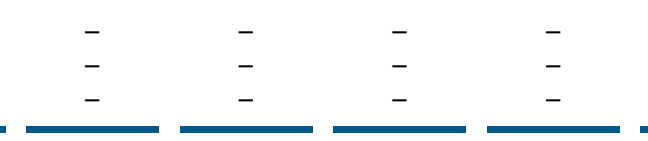

$\begin{array}{r}1.0 \\ 10.5 \\ 2.9 \\ \hline\end{array}$

\begin{tabular}{l}
0.7 \\
8.7 \\
0.8 \\
\hline
\end{tabular}

\begin{tabular}{ll}
0.8 & - \\
9.6 & - \\
1.0 & - \\
\hline
\end{tabular}

adopted from Taiwan, therefore clinical information concerning birth and height and proportions of the parents is missing.

${ }^{\mathrm{b}}$ Patients treated with $\mathrm{GH}$.

'Patients 5 and 6 are siblings.

For all patients from groups 1 and 2, irrespective of pubertal status during treatment, numerical data are shown in Supplementary Table 1, see section on supplementary data given at the end of this article, and graphical representations in Supplementary Figures 2 and 3. All parameters of the growth response and responsiveness in the 1st year of GH treatment were significantly greater for group 2 compared with group 1.

Only three patients from group 3 (SDUP), all prepubertal, were treated with $\mathrm{GH}$, and their response is shown in Table 2 . In the 1 st year of GH treatment, these patients gained on average 0.8 SDS in height and achieved a $\mathrm{HV}$ of $9.6 \mathrm{~cm}$ in 1 year, which is similar to patients from groups 1 and 2 . Because of the uncertainty about the pathogenicity of these duplications, and the small number of patients, no further statistical analysis was carried out.

\section{Effect of GH on serum IGF1, skeletal maturation, and body proportions}

Serum IGF1 SDS (mean \pm s.D.) increased similarly in groups 1 and $2(2.4 \pm 1.0, n=29$ and $2.4 \pm 0.9, n=9$ respectively). Baseline median IGF1 was -0.4 SDS (range -3.3 to 0.9 SDS) and on treatment median (s.D.) serum IGF1 was 1.9 (range 0 to 2.9 SDS), after a median treatment duration of $2.7(0.2-5)$ years. The ratio between BA and CA increased by 0.1 in both groups over a median duration of 2.7 years (range 1-5 years after start GH treatment), and body proportions did not significantly change during treatment $(\Delta \mathrm{SH} /$ height ratio SDS of 0.4 and -0.1 in groups 1 and 2 , respectively). There were no significant differences between the two groups.

\section{Discussion}

Children with a deletion of the SHOX enhancer region are equally short, but less disproportionate than patients with a SHOX deletion or point mutation and have a similar frequency of Madelung deformity. Their parents carrying the variant are less short and disproportionate than parents carrying a SHOX deletion or point mutation. For children who remained prepubertal during GH treatment, the growth response was slightly, but statistically significantly, greater in patients with SEDs, even though the serum IGF1 response was similar for both groups. The growth response of patients with SHI was similar to that reported previously (16). 
Table 3 Clinical characteristics at start of $\mathrm{GH}$ and growth response to $\mathrm{GH}$ in prepubertal patients with $\mathrm{SHOX}$ mutations and deletions and SHOX enhancer deletions, mean (S.D.).

\begin{tabular}{|c|c|c|c|c|c|c|c|c|}
\hline Clinical characteristics & $n$ & All patients & Range & $n$ & $\begin{array}{c}\text { SHOX } \\
\text { mutations } \\
\text { and deletions }\end{array}$ & $n$ & $\begin{array}{l}\text { SHOX upstream and } \\
\text { downstream } \\
\text { enhancer deletions }\end{array}$ & $P^{*}$ \\
\hline \multicolumn{9}{|l|}{ At start of $\mathrm{GH}$} \\
\hline Age (years) & 33 & $8.07(2.3)$ & $4.0 ; 12.1$ & 25 & $8.21(2.2)$ & 8 & 7.65 (2.7) & 0.585 \\
\hline Male/female & & $13 / 20$ & & & $8 / 17$ & & $5 / 3$ & 0.130 \\
\hline Height SDS & 33 & $-2.8(0.7)$ & $-4.3 ;-1.8$ & 25 & $-2.9(0.7)$ & 8 & $-2.6(0.6)$ & 0.227 \\
\hline $\begin{array}{l}\text { HV year before GH } \\
\text { (cm/year) }\end{array}$ & 28 & $5.4(1.1)$ & $3.1 ; 7.2$ & 20 & $5.1(1.0)$ & 8 & $6.1(0.8)$ & 0.042 \\
\hline HV SDS before GH & 28 & $-0.5(1.0)$ & $-2.8 ; 1.2$ & 20 & $-0.7(1.0)$ & 8 & $0.0(0.8)$ & 0.075 \\
\hline BMI SDS & 33 & $0.6(0.9)$ & $-1.4 ; 2.7$ & 25 & $0.7(1.0)$ & 8 & $0.4(0.7)$ & 0.581 \\
\hline IGF1 SDS & 29 & $-1.0(1.1)$ & $-3.3 ; 0.7$ & 22 & $-0.9(1.2)$ & 7 & $-1.5(0.5)$ & 0.053 \\
\hline IGFBP3 SDS & 9 & $0.1(0.8)$ & $-1.6 ; 1.1$ & 5 & $-0.2(0.9)$ & 4 & $0.4(0.7)$ & 0.327 \\
\hline BA/CA ratio & 21 & $0.9(0.1)$ & $0.5 ; 1.1$ & 15 & $0.9(0.1)$ & 6 & $0.8(0.2)$ & 0.099 \\
\hline $\mathrm{GH}$ dose $\left(\mathrm{mg} / \mathrm{m}^{2}\right.$ per day) & 33 & $1.24(0.2)$ & $0.6 ; 2.0$ & 25 & $1.27(0.2)$ & 8 & $1.14(0.2)$ & 0.179 \\
\hline $\mathrm{GH}$ dose $(\mu \mathrm{g} / \mathrm{kg}$ per day) & 33 & $48.0(9.4)$ & $28.6 ; 77.2$ & 25 & $49.1(10.0)$ & 8 & $44.7(6.5)$ & 0.208 \\
\hline \multicolumn{9}{|l|}{ After 1 year of $\mathrm{GH}$ therapy } \\
\hline $\mathrm{HV}$ (cm/year) & 28 & $9.2(1.3)$ & $7.0 ; 12.8$ & 20 & $8.9(1.0)$ & 8 & $10.2(1.6)$ & 0.028 \\
\hline HV SDS & 28 & $3.5(1.9)$ & $0.2 ; 8.6$ & 20 & $3.1(1.6)$ & 8 & $4.6(2.3)$ & 0.048 \\
\hline$\Delta$ Height SDS & 33 & $0.6(0.2)$ & $0.2 ; 1.2$ & 25 & $0.6(0.2)$ & 8 & $0.8(0.3)$ & 0.036 \\
\hline IoR & 28 & $0.9(0.9)$ & $-0.8 ; 3.2$ & 20 & $0.6(0.7)$ & 8 & $1.5(1.0)$ & 0.053 \\
\hline \multicolumn{9}{|l|}{ After 2 years of GH therapy } \\
\hline $\mathrm{HV}$ (cm/year) & 19 & $7.9(1.9)$ & $4.4 ; 14.1$ & 13 & $7.7(0.9)$ & 6 & $8.3(3.2)$ & 0.537 \\
\hline HV SDS & 19 & $2.5(2.1)$ & $-1.2 ; 9.4$ & 13 & $2.2(1.0)$ & 6 & $3.1(3.6)$ & 0.396 \\
\hline$\Delta$ Height SDS & 23 & $0.3(0.2)$ & $-0.3 ; 0.6$ & 17 & $0.3(0.1)$ & 6 & $0.3(0.3)$ & 0.731 \\
\hline IoR & 19 & $0.9(1.6)$ & $-1.8 ; 6.2$ & 13 & $0.7(0.8)$ & 6 & $1.2(2.7)$ & 0.930 \\
\hline \multicolumn{9}{|l|}{ After 3 years of GH therapy } \\
\hline $\mathrm{HV}$ (cm/year) & 14 & $6.9(0.9)$ & $5.3 ; 8.2$ & 9 & $6.7(0.9)$ & 5 & $7.2(0.7)$ & 0.292 \\
\hline HV SDS & 14 & $1.6(1.1)$ & $0.1 ; 3.6$ & 9 & $1.5(1.1)$ & 5 & $1.7(1.3)$ & 0.739 \\
\hline$\Delta$ Height SDS & 15 & $0.3(0.2)$ & $0 ; 0.5$ & 10 & $0.2(0.2)$ & 5 & $0.3(0.2)$ & 0.635 \\
\hline loR & 14 & $0.6(0.9)$ & $-1.3 ; 1.6$ & 9 & $0.5(0.8)$ & 5 & $0.8(1.2)$ & 0.463 \\
\hline \multicolumn{9}{|l|}{ After 4 years of GH therapy } \\
\hline $\mathrm{HV}(\mathrm{cm} /$ year) & 11 & $6.2(0.9)$ & $4.7 ; 7.7$ & 8 & $6.0(0.9)$ & 3 & $7.0(0.7)$ & 0.066 \\
\hline HV SDS & 11 & $0.8(0.8)$ & $-0.2 ; 2.8$ & 8 & $0.5(0.4)$ & 3 & $1.7(0.9)$ & 0.014 \\
\hline$\Delta$ Height SDS & 11 & $0.2(0.2)$ & $-0.1 ; 0.6$ & 8 & $0.1(0.1)$ & 3 & $0.3(0.2)$ & 0.074 \\
\hline IoR & 11 & $0.5(0.9)$ & $-0.9 ; 1.8$ & 8 & $0.3(0.9)$ & 3 & $0.9(0.7)$ & 0.414 \\
\hline
\end{tabular}

*P value from $t$-test comparing patients with SHOX mutations and deletions to patients with SHOX upstream and downstream enhancer deletions.

The results of genetic testing in our patients, showing deletions of SHOX and its enhancer in 35 and 22 out of 74 families (47 and 30\% respectively), far more than SHOX point mutations (10/74 families, 14\%), demonstrates the efficiency of our stepwise diagnostic approach, consisting of an MLPA for the detection of copy number variants followed by Sanger sequencing. Deletions of $S H O X$ or its enhancer region were found in around $80 \%$ of patients in other reports as well $(34,35)$.

Our findings confirm those of previous reports $(5,6$, 10) that patients with SEDs show a similar degree of short stature compared to patients with SHI. We also confirm the remarkable heterogeneity of statural growth in carriers of SHOX defects both in probands and affected parents, as well as in carriers of SEDs. Similarly to body stature, as well as for body proportions, the variability was wide for both groups. Patients with SEDs were on average less disproportionate than patients with SHI if the SH/height ratio and the extremities/trunk ratio were taken as criteria, but the arm span/height ratio was not different. Consistent with an earlier report (35), patients with SEDs also had a slightly lower BMI than patients with SHI, although mean BMI SDS in both groups was close to average for the population. These observations suggest that the predictive value of a BMI above the mean as part of the clinical score developed by Rappold et al. (36) may have been overestimated and that normal body proportions should not be considered a contraindication for $S H O X$ testing.

While duplications of $S H O X$ have been reported to be associated with normal to tall stature $(37,38,39)$, there are also reports on a possible association with short stature $(12,13,14)$. In one of these reports, it was hypothesized 

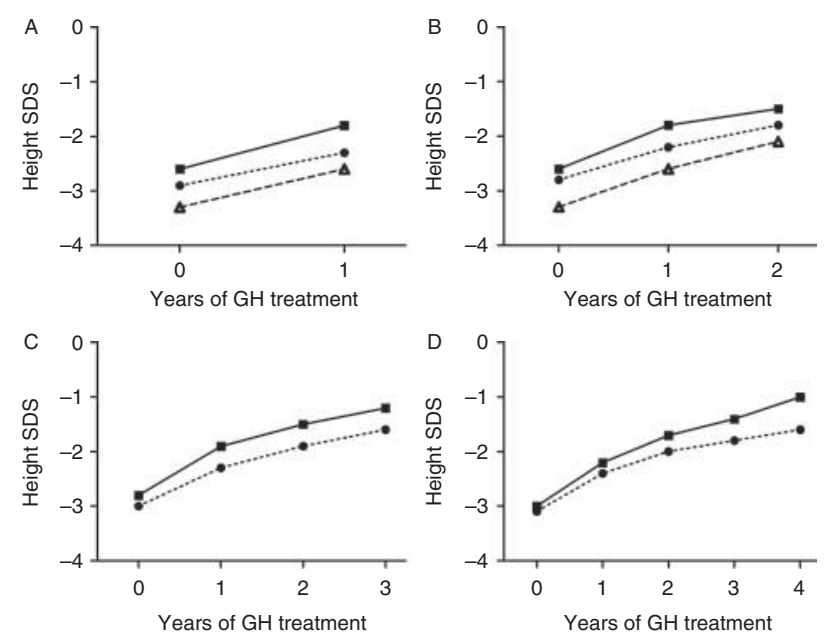

Figure 2

Mean height SDS in children of groups 1 and 2 who remained prepubertal during GH treatment in four cohorts (followed for 1-4 years). The dotted lines with circles represent group 1, the lines with squares group 2 , and the dashed lines with triangles represent data as reported by Blum et al. (16). One year of GH treatment (A): group $1(n=25)$ and group $2(n=8)$. Two years of GH treatment (B): group $1(n=17)$ and group $2(n=6)$.

Three years of $\mathrm{GH}$ treatment (C): group $1(n=10)$ and group 2 $(n=5)$. Four years of $\mathrm{GH}$ treatment $(D)$ : group $1(n=8)$ and group $2(n=3)$.

that patients with smaller duplications may be more severely affected than patients with larger duplications (13). In another report (12), it was speculated that patients with duplications which included the SHOX enhancer could impair gene regulation by interfering with the three dimensional chromatin spatial organization, resulting in impaired contact between the enhancer and promoter (40). The phenotype of these patients is quite variable $(13,39)$, and the clinical characteristics of patients with duplications of only the SHOX downstream enhancer region have not been described so far. Based on these reports, we tried to collect as much as possible clinical information about the children and their parents with SHOX duplications $(n=5)$ and duplications of the enhancer region $(n=9)$ (Table 2$)$. HtSDS in our patients ranged from -3.5 to -2.2 , and $\mathrm{SH} /$ height SDS from 0.7 to 1.9. HtSDS of parents carrying the duplication varied from -2.5 to +1.2 SDS and in unaffected parents from -3.5 to -0.5 . In some patients a causal association between the SHOX duplication and the child's short stature appeared unlikely, for example, in the child born severely small for gestational age (SGA) with normal body proportions and a normally statured parent carrying a small duplication (Table 2, case 8). Even though the absence of body disproportion might be partially explained by the young age of the majority of these children, the observation that body disproportion is absent in all children, and the absence of clinical features in their parents, cast doubt on the pathogenicity of these genetic variants.

This is the first study assessing the effect of $\mathrm{GH}$ treatment in patients with SEDs in comparison with SHI. The growth response in patients with SHI was similar to previously reported data (16), but the conventional outcome measures of the 1st year growth response (height velocity, height velocity SDS, and change in HtSDS) showed a greater effect in prepubertal patients with SEDs. The GH dose between the two groups was similar, and the recommended dose for SHI as reported by Blum et al. (16), seems efficacious for patients with SHOX defects as well as enhancer deletions. Since the growth response in patients
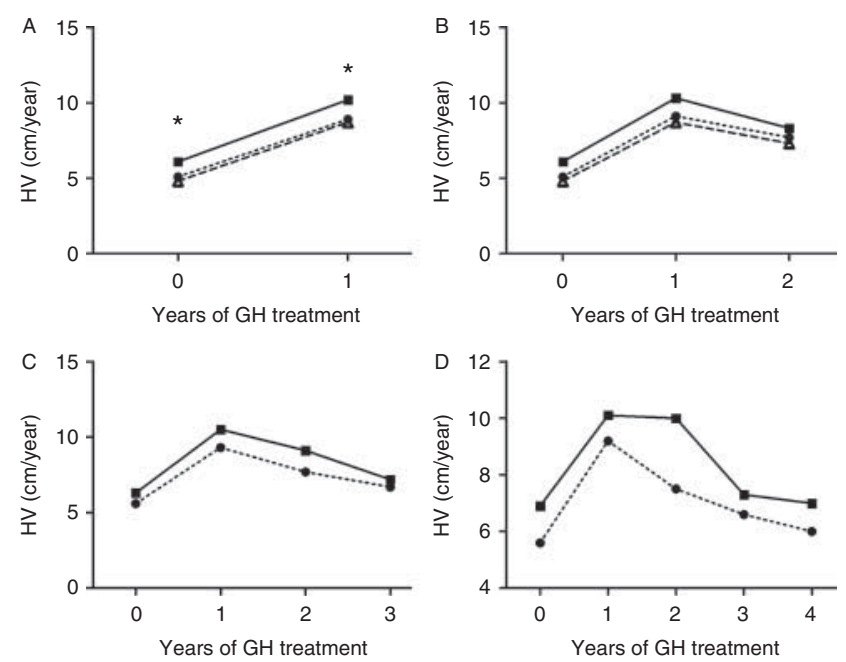

Figure 3

Mean height velocities in children of groups 1 and 2 who remained prepubertal during $\mathrm{GH}$ treatment in four cohorts (followed for 1-4 years). The dotted lines with circles represent group 1, the lines with squares group 2, and the dashed lines with triangles represent data as reported by Blum et al. (16). One year of GH treatment (A): group $1(n=20)$ and group 2 $(n=8)$. Two years of $\mathrm{GH}$ treatment $(\mathrm{B})$ : group $1(n=13)$ and group $2(n=6)$. Three years of $\mathrm{GH}$ treatment $(\mathrm{C})$ : group $1(n=9)$ and group $2(n=5)$. Four years of $\mathrm{GH}$ treatment (D): group 1 $(n=8)$ and group $2(n=3)$. Statistically significant differences are indicated with an asterisk. 
with SHI has been reported as similar to that of girls with Turner syndrome, we used the prediction models for Turner syndrome (20) to calculate the IoR. The IoR in group 2 was slightly higher than the IoR in group 1 , but this difference was not significantly different in prepubertal children. The IoR was, however, significantly different if all patients were included, regardless of their pubertal status. The reason why children with SEDs seem to respond slightly greater to GH treatment remains unclear. We speculate that if $\mathrm{GH}$, via downstream GH-dependent transcription factors, promotes expression of $S H O X$, the presence of two intact (functional) copies of SHOX in SED may cause a higher responsiveness to GH. Another possible explanation for the higher responsiveness to GH could be that SHOX deficiency is less severe in the presence of enhancer deletions. This hypothesis would explain the lower degree of skeletal disproportion and Madelung deformity observed, but not the same degree of short stature.

This study has several limitations. First, there may be an ascertainment bias towards patients with typical clinical features of LWS, because screening for SHOX deficiency is not performed routinely in all cases of short stature. Second, due to the retrospective character of the study, not all variables were available and we had to depend on data as reported by multiple physicians. Third, we were only able to investigate $40 \%$ of potentially eligible cases. However, it seems unlikely that this has generated sampling bias. Fourth, similarly to previous studies, the effect of GH treatment could not be compared with untreated controls. However, our data are well in line with previous reports $(16,17)$, and there is little doubt that GH is effective for this indication. Finally, the number of patients with $S H O X$ or SHOX enhancer duplications was too small to draw any firm conclusion on the pathogenicity of these duplications, and on their growth response to GH treatment.

In conclusion, we show that children with SEDs are less disproportionate than children with SHI, and that in both groups HtSDS and body proportions vary widely. Children with a SED show a slightly greater growth response to GH treatment than children with SHI. The clinical significance of SDUPs remains uncertain.

Supplementary data

This is linked to the online version of the paper at http://dx.doi.org/10.1530/ EJE-15-0451.

Declaration of interest

S H Donze, C R Meijer, S G Kant, G R J Zandwijken, A H van der Hout, R M L van Spaendonk, A M W van den Ouweland, and M Losekoot have nothing to disclose. J M Wit consults for OPKO, Versartis, Biopartners, and MerckSerono. W Oostdijk received unrestricted grant support from Novo Nordisk and Ferring.

\section{Funding}

This research did not receive any specific grant from any funding agency in the public, commercial or not-for-profit sector.

\section{Acknowledgements}

We thank all patients who participated in the study and their families. We also thank all physicians who helped collecting patient information (in alphabetical order): A A E M van Alfen-van der Velden (Radboud University Medical Center, Nijmegen), R Dekkers (Maasziekenhuis Pantein, Boxmeer), A J van Essen, E H Gerkes (University Medical Center, Groningen), J J Gosen (Rijnland Hospital, Leiderdorp), G A P T Hurkx (Elkerliek Hospital, Helmond), H J van der Kamp (University Medical Center Utrecht), J M van de Kamp (VU University Medical Center, Amsterdam), M KempersMatthijsse (Radboud University Medical Center, Nijmegen), M J KoenenJacobs (Maasziekenhuis Pantein, Boxmeer), C R W Korver (Kennemer Gasthuis, Haarlem), A M A Lachmeijer (VU University Medical Center, Amsterdam), A Molendijk (Rivierenland Hospital, Tiel), P W J Mossevelde (Amphia Hospital, Breda), D Mul (Juliana Children's Hospital, The Hague), S de Munnik (Radboud University Medical Center, Nijmegen), R J H Odink (Catharina Hospital, Eindhoven), P Rump (University Medical Center, Groningen), T C J Sas (Erasmus Medical Center, Rotterdam), J J SchermerRotte (St. Elisabeth Hospital, Tilburg), G Shabo (Ziekenhuisgroep Twente, Almelo), M E H Simon (Erasmus MC, Rotterdam), P J H M Stouthart (Orbis Medical Center), C H Tibosch (Antonius Hospital, Sneek), J B G M Verheij (University Medical Center, Groningen), and A F Verhoeven-van Lieburg (Maasziekenhuis Pantein, Boxmeer).

\section{References}

1 Sabherwal N, Bangs F, Roth R, Weiss B, Jantz K, Tiecke E, Hinkel GK, Spaich C, Hauffa BP, van der Kamp H et al. Long-range conserved non-coding SHOX sequences regulate expression in developing chicken limb and are associated with short stature phenotypes in human patients. Human Molecular Genetics 200716 210-222. (doi:10.1093/hmg/ddl470)

2 Benito-Sanz S, Thomas NS, Huber C, Gorbenko del Blanco D, Aza-Carmona M, Crolla JA, Maloney V, Rappold G, Argente J, Campos-Barros A et al. A novel class of pseudoautosomal region 1 deletions downstream of SHOX is associated with Leri-Weill dyschondrosteosis. American Journal of Human Genetics $2005 \mathbf{7 7}$ 533-544. (doi:10.1086/449313)

3 Rao E, Weiss B, Fukami M, Rump A, Niesler B, Mertz A, Muroya K, Binder G, Kirsch S, Winkelmann $\mathrm{M}$ et al. Pseudoautosomal deletions encompassing a novel homeobox gene cause growth failure in idiopathic short stature and Turner syndrome. Nature Genetics 199716 54-63. (doi:10.1038/ng0597-54)

4 Kant SG, van der Kamp HJ, Kriek M, Bakker E, Bakker B, Hoffer MJ, van Bunderen $\mathrm{P}$, Losekoot M, Maas SM, Wit JM et al. The jumping SHOX gene - crossover in the pseudoautosomal region resulting in unusual inheritance of Leri-Weill dyschondrosteosis. Journal of Clinical Endocrinology and Metabolism 201196 E356-E359. (doi:10.1210/ jc.2010-1505)

5 Fukami M, Kato F, Tajima T, Yokoya S \& Ogata T. Transactivation function of an approximately 800-bp evolutionarily conserved sequence at the SHOX $3^{\prime}$ region: implication for the downstream 
enhancer. American Journal of Human Genetics 200678 167-170. (doi:10.1086/499254)

6 Chen J, Wildhardt G, Zhong Z, Roth R, Weiss B, Steinberger D, Decker J, Blum WF \& Rappold G. Enhancer deletions of the SHOX gene as a frequent cause of short stature: the essential role of a $250 \mathrm{~kb}$ downstream regulatory domain. Journal of Medical Genetics 200946 834-839. (doi:10.1136/jmg.2009.067785)

7 Durand C, Bangs F, Signolet J, Decker E, Tickle C \& Rappold G. Enhancer elements upstream of the SHOX gene are active in the developing limb. European Journal of Human Genetics 201018 527-532. (doi:10.1038/ejhg.2009.216)

8 Kenyon EJ, McEwen GK, Callaway H \& Elgar G. Functional analysis of conserved non-coding regions around the short stature hox gene (shox) in whole zebrafish embryos. PLoS ONE 20116 e21498. (doi:10.1371/ journal.pone.0021498)

9 Evers C, Heidemann PH, Dunstheimer D, Schulze E, Haag C, Janssen JW, Fischer C, Jauch A \& Moog U. Pseudoautosomal inheritance of Leri-Weill syndrome: what does it mean? Clinical Genetics 201179 489-494. (doi:10.1111/j.1399-0004.2010.01488.x)

10 Kant SG, Broekman SJ, de Wit CC, Bos M, Scheltinga SA, Bakker E, Oostdijk W, van der Kamp HJ, van Zwet EW, van der Hout AH et al. Phenotypic characterization of patients with deletions in the $3^{\prime}$ flanking SHOX region. PeerJ 20131 e35. (doi:10.7717/peerj.35)

11 Benito-Sanz S, Royo JL, Barroso E, Paumard-Hernandez B, Barreda-Bonis AC, Liu P, Gracia R, Lupski JR, Campos-Barros A, Gomez-Skarmeta JL et al. Identification of the first recurrent PAR1 deletion in Leri-Weill dyschondrosteosis and idiopathic short stature reveals the presence of a novel SHOX enhancer. Journal of Medical Genetics 201249 442-450. (doi:10.1136/jmedgenet2011-100678)

12 Iughetti L, Capone L, Elsedfy H, Bertorelli R, Predieri B, Bruzzi P, Forabosco A \& El Kholy M. Unexpected phenotype in a boy with trisomy of the SHOX gene. Journal of Pediatric Endocrinology \& Metabolism 201023 159-169. (doi:10.1515/JPEM.2010.23.1-2.159)

13 Benito-Sanz S, Barroso E, Heine-Suner D, Hisado-Oliva A, Romanelli V, Rosell J, Aragones A, Caimari M, Argente J, Ross JL et al. Clinical and molecular evaluation of SHOX/PAR1 duplications in Leri-Weill dyschondrosteosis (LWD) and idiopathic short stature (ISS). Journal of Clinical Endocrinology and Metabolism 201196 E404-E412. (doi:10.1210/jc.2010-1689)

14 Caliebe J, Broekman S, Boogaard M, Bosch CA, Ruivenkamp CA, Oostdijk W, Kant SG, Binder G, Ranke MB, Wit JM et al. IGF1, IGF1R and SHOX mutation analysis in short children born small for gestational age and short children with normal birth size (idiopathic short stature). Hormone Research in Paediatrics 201277 250-260. (doi:10.1159/000338341)

15 Wit JM, van Duyvenvoorde HA, van Klinken JB, Caliebe J, Bosch CA, Lui JC, Gijsbers AC, Bakker E, Breuning MH, Oostdijk W et al. Copy number variants in short children born small for gestational age. Hormone Research in Paediatrics 201482 310-318. (doi:10.1159/ 000367712)

16 Blum WF, Crowe BJ, Quigley CA, Jung H, Cao D, Ross JL, Braun L \& Rappold G. Growth hormone is effective in treatment of short stature associated with short stature homeobox-containing gene deficiency: two-year results of a randomized, controlled, multicenter trial. Journal of Clinical Endocrinology and Metabolism 200792 219-228. (doi:10.1210/jc.2006-1409)

17 Massart F, Bizzi M, Baggiani A \& Miccoli M. Height outcome of the recombinant human growth hormone treatment in patients with SHOX gene haploinsufficiency: a meta-analysis. Pharmacogenomics 201314 607-612. (doi:10.2217/pgs.13.44)

18 Bunyan DJ, Baker KR, Harvey JF \& Thomas NS. Diagnostic screening identifies a wide range of mutations involving the SHOX gene, including a common $47.5 \mathrm{~kb}$ deletion $160 \mathrm{~kb}$ downstream with a variable phenotypic effect. American Journal of Medical Genetics. Part A 2013 161A 1329-1338. (doi:10.1002/ajmg.a.35919)
19 Prader A, Largo RH, Molinari L \& Issler C. Physical growth of Swiss children from birth to 20 years of age. First Zurich longitudinal study of growth and development. Helvetica Paediatrica Acta. Supplementum 1989 52 1-125.

20 Ranke MB, Lindberg A, Brosz M, Kaspers S, Loftus J, Wollmann H, Koltowska-Haggstrom M \& Roelants M. Accurate long-term prediction of height during the first four years of growth hormone treatment in prepubertal children with growth hormone deficiency or Turner syndrome. Hormone Research in Paediatrics 201278 8-17. (doi:10.1159/ 000339468)

21 Blum WF, Ross JL, Zimmermann AG, Quigley CA, Child CJ, Kalifa G, Deal C, Drop SL, Rappold G \& Cutler GB Jr. GH treatment to final height produces similar height gains in patients with SHOX deficiency and Turner syndrome: results of a multicenter trial. Journal of Clinical Endocrinology and Metabolism 201398 E1383-E1392. (doi:10.1210/jc. 2013-1222)

22 Ranke MB \& Lindberg A. Observed and predicted growth responses in prepubertal children with growth disorders: guidance of growth hormone treatment by empirical variables. Journal of Clinical Endocrinology and Metabolism 201095 1229-1237. (doi:10.1210/ jc.2009-1471)

23 Ranke MB, Lindberg A, Chatelain P, Wilton P, Cutfield W, AlbertssonWikland K \& Price DA. Prediction of long-term response to recombinant human growth hormone in Turner syndrome: development and validation of mathematical models. KIGS International Board. Kabi International Growth Study. Journal of Clinical Endocrinology and Metabolism 200085 4212-4218. (doi:10.1210/jcem.85.11.6976)

24 Ranke MB \& Lindberg A. Predicting growth in response to growth hormone treatment. Growth Hormone \& IGF Research 2009 19 1-11. (doi:10.1016/j.ghir.2008.08.001)

25 Fredriks AM, van Buuren S, van Heel WJ, Dijkman-Neerincx RH, Verloove-Vanhorick SP \& Wit JM. Nationwide age references for sitting height, leg length, and sitting height/height ratio, and their diagnostic value for disproportionate growth disorders. Archives of Disease in Childhood 200590 807-812. (doi:10.1136/adc.2004.050799)

26 Schonbeck Y, Talma H, van Dommelen P, Bakker B, Buitendijk SE, HiraSing RA \& van Buuren S. The world's tallest nation has stopped growing taller: the height of Dutch children from 1955 to 2009. Pediatric Research 201373 371-377. (doi:10.1038/pr.2012.189)

27 van Dommelen P, Schonbeck Y \& van Buuren S. A simple calculation of the target height. Archives of Disease in Childhood 201297182. (doi:10.1136/archdischild-2011-301095)

28 Cole TJ \& Roede MJ. Centiles of body mass index for Dutch children aged 0-20 years in $1980-$ a baseline to assess recent trends in obesity. Annals of Human Biology 199926 303-308. (doi:10.1080/ 030144699282633)

29 Niklasson A, Ericson A, Fryer JG, Karlberg J, Lawrence C \& Karlberg P. An update of the Swedish reference standards for weight, length and head circumference at birth for given gestational age (1977-1981). Acta Paediatrica Scandinavica 199180 756-762. (doi:10.1111/j.1651-2227. 1991.tb11945.x)

30 Rikken B, van Doorn J, Ringeling A, Van den Brande JL, Massa G \& Wit JM. Plasma levels of insulin-like growth factor (IGF)-I, IGF-II and IGF-binding protein-3 in the evaluation of childhood growth hormone deficiency. Hormone Research 199850 166-176. (doi:10.1159/ 000023268)

31 Binder G, Ranke MB \& Martin DD. Auxology is a valuable instrument for the clinical diagnosis of SHOX haploinsufficiency in school-age children with unexplained short stature. Journal of Clinical Endocrinology and Metabolism 200388 4891-4896. (doi:10.1210/ jc.2003-030136)

32 Freeman JV, Cole TJ, Chinn S, Jones PR, White EM \& Preece MA. Cross sectional stature and weight reference curves for the UK, 1990. Archives of Disease in Childhood 199573 17-24. (doi:10.1136/adc.73.1.17)

33 Cole TJ. Some questions about how growth standards are used. Hormone Research 199645 (Suppl 2) 18-23. (doi:10.1159/000184843) 
34 Binder G. Short stature due to SHOX deficiency: genotype, phenotype, and therapy. Hormone Research in Paediatrics 201175 81-89. (doi:10.1159/000324105)

35 Rosilio M, Huber-Lequesne C, Sapin H, Carel JC, Blum WF \& Cormier-Daire V. Genotypes and phenotypes of children with SHOX deficiency in France. Journal of Clinical Endocrinology and Metabolism 201297 E1257-E1265. (doi:10.1210/jc.2011-3460)

36 Rappold G, Blum WF, Shavrikova EP, Crowe BJ, Roeth R, Quigley CA, Ross JL \& Niesler B. Genotypes and phenotypes in children with short stature: clinical indicators of SHOX haploinsufficiency. Journal of Medical Genetics 200744 306-313. (doi:10.1136/jmg.2006.046581)

37 Ogata T, Matsuo N \& Nishimura G. SHOX haploinsufficiency and overdosage: impact of gonadal function status. Journal of Medical Genetics 200138 1-6. (doi:10.1136/jmg.38.1.1)
38 Adamson KA, Cross I, Batch JA, Rappold GA, Glass IA \& Ball SG. Trisomy of the short stature homeobox-containing gene (SHOX), resulting from a duplication-deletion of the $\mathrm{X}$ chromosome. Clinical Endocrinology 200256 671-675. (doi:10.1046/j.1365-2265. 2002.01504.x)

39 Thomas NS, Harvey JF, Bunyan DJ, Rankin J, Grigelioniene G, Bruno DL, Tan TY, Tomkins S \& Hastings R. Clinical and molecular characterization of duplications encompassing the human SHOX gene reveal a variable effect on stature. American Journal of Medical Genetics. Part A 2009 149A 1407-1414. (doi:10.1002/ ajmg.a.32914)

40 Li Q, Barkess G \& Qian H. Chromatin looping and the probability of transcription. Trends in Genetics 200622 197-202. (doi:10.1016/j.tig. 2006.02.004)

Received 1 May 2015

Revised version received 7 July 2015

Accepted 11 August 2015 